\title{
Geographical divide led inequality in accessing maternal healthcare services between hills and valley regions of Manipur state, India
}

\author{
Prem Shankar Mishra ${ }^{a}$, N. Pautunthang ${ }^{a}$, Strong P. Marbaniang ${ }^{\text {b, }}$, Anushree K. $\mathrm{N}^{\mathrm{c}}$ \\ ${ }^{a}$ PhD Research Scholar, Population Research Centre, Institute for Social and Economic Change, Bengaluru, 560072, Karnataka, India \\ ${ }^{\mathrm{b}}$ PhD Research Scholar, Department of Public Health \& Mortality Studies, International Institute for Population Sciences, Mumbai, 400088, Maharashtra, India \\ ${ }^{\text {c } P h D ~ R e s e a r c h ~ S c h o l a r, ~ C e n t e r ~ f o r ~ E c o n o m i c ~ S t u d i e s ~ a n d ~ P o l i c y, ~ I n s t i t u t e ~ f o r ~ S o c i a l ~ a n d ~ E c o n o m i c ~ C h a n g e, ~ B e n g a l u r u, ~ 560072, ~ K a r n a t a k a, ~ I n d i a ~}$
}

\section{A R T I C L E I N F O}

\section{Keywords:}

Ante natal care

Post natal care

Institutional delivery

Manipur

Health inequality

\begin{abstract}
A B S T R A C T
Geographically, Manipur is composed of two sets of landmasses known as the valley and the hills districts. As compared to the valley districts, the hilly district is largely remained undeveloped and lack basic infrastructure and services like healthcare facilities, educational institutions, public distribution system, transportation, etc. Little is known about the differentials in the utilization of maternal healthcare services between the hills and the valley of Manipur state of India. The paper tries to understand the inequalities in accessing maternal healthcare services between the hills and valleys region. Logistic regression and concentration index was adopted to assess the utilization of maternal healthcare services. Results indicate low utilization of maternal healthcare services in the hilly region, with only $19 \%, 22 \%$, and $21 \%$ have access to $4+$ ANC visit, institutional delivery, and PNC visits respectively. The odds of utilizing 4+ ANC visits [Odds Ratio (OR): 0.47, Confidence Interval (C.I):0.26-0.82], Institutional delivery [OR: 0.42, C.I:0.28-0.62], and PNC visits [OR: 0.42, C.I:0.28-0.60] were less likely in the hilly region as compared to the valley region. Valley region indicates low inequality in accessing maternal healthcare services, however high inequality in accessing to institutional delivery and PNC visits was observed in the hilly region. Inequality is significantly higher in hilly areas $\left(\mathrm{CI}_{\mathrm{ANC}}: 0.276 ; \mathrm{CI}_{\text {inst.delivery }}: 0.277 ; \mathrm{CI}_{\mathrm{PNC}}: 0.206\right)$ than in valley regions $\left(\mathrm{CI}_{\mathrm{ANC}}: 0.070 ; \mathrm{CI}_{\text {inst.delivery }} 0.088 ; \mathrm{CI}_{\mathrm{PNC}_{\mathrm{C}}}: 0.081\right)$. Further, mother education, household wealth, and exposure to television are the main contributor to inequality. Better educational opportunities and economic activities may improve the utilization of maternal health services.
\end{abstract}

\section{Introduction}

Geographically, Manipur is composed of two sets of landmasses popularly known as the valley and the hills. The hills are occupied by the tribals and the valley is occupied by the non-tribal Meiteis. In terms of population, Meiteis are the dominant community and had a fair amount of political dominance with socio-economically development. ${ }^{1}$ Moreover, they live in the valley which is highly fertile as a result, they are more prosperous than tribals who live mostly in hill areas. ${ }^{2}$ Hill areas in Manipur are largely remained undeveloped and lack basic infrastructure and services like healthcare facilities, educational institutions, public distribution system, transportation, etc. On the other hand, the Valley districts of Manipur are among the most developed districts in Northeast India. ${ }^{2}$ Health inequalities which differ mainly across space and socio-economic inequalities are often disadvantageous to the hilly people. ${ }^{32}$ The child mortality rate was higher in the hill community. ${ }^{3}$ According to NFHS-4, the highest degree of fertility (TFR) is among the projected tribe (3.19) who are predominantly Christians (3.18) living in the hill districts. The current use of family planning method is still very low in the hill districts like Chandel (15.4\%) and Ukhrul (12.7\%). ${ }^{4}$ In the hill districts like Chandel, Senapati, Tamenglong and Ukhrul, institutional delivery is less than $40 \%$. Further, the condition in the hills was further worsened during the COVID-19 pandemic. For instance, tribal women from the hill district died with her unborn child due to denied treatment by the Imphal valley-based hospitals. ${ }^{2,5}$

There is plenty of literature that talks about inequality between the hills and the valley in terms of development. In most of the research regarding the hills-valley divide, the focus has been given to ethnic conflict and political demands ${ }^{3,6-8}$. However, there is no substantial literature on the disparity between Hills and Valleys in the context of

\footnotetext{
* Corresponding author.

E-mail addresses: psmishrabhu@gmail.com (P.S. Mishra), naulakzomi@googlemail.com (N. Pautunthang), marbaniangstrong@gmail.com (S.P. Marbaniang), anushreekashyap91@gmail.com (A.K. N).
} 
maternal health care services. Little is known about the differentials in the utilization of maternal healthcare services between the hills and the valley of Manipur state of India. The disparity in maternal healthcare services between hills and valleys received little attention in academic research. Therefore the present paper tries to understand the inequalities in maternal healthcare services between the hills and valleys in the Manipur state of India.

\section{Material and methods}

The data from the National Family Health Survey round four (NFHS4) was used to understand maternal healthcare service utilization in the Manipur state of India. ${ }^{4}$ NFHS is a cross-sectional national representative survey, conducted in 2015-16 under the stewardship of the Ministry of Health and Family Welfare (MoHFW), Government of India. NFHS used a two-stage stratified sampling design in both rural and urban areas to give the estimates at state as well as district level.

\subsection{Inclusion and exclusion criteria}

Only women belonging to the states of Manipur were included in the study, which results to a total sample size of 5636 ever-married women between the age of 15-49. Further, women living in the hilly region are those women from the districts of Chandel, Tamenglong, Ukhrul, Senapati, and Churachandpur. Women living in the valley region are those women from the districts of Imphal West, Imphal East, Bishnupur, and Thoubal.

\subsection{Outcome variables}

To analysis, the maternal healthcare services, key outcomes variables are used such as four and more ante-natal care (ANC), institutional delivery (both public and private) and post natal care (PNC). In the context of PNC services, women who had given birth in the five years preceding the survey were asked "Did you have any check-up within 42 $\mathrm{h}$ after delivery?" and "How many days after delivery did the first checkup take place?" In this study, women who went for a check-up to health facilities or saw a doctor within two weeks of delivery are considered to have used PNC services. The nature of outcomes variables are dummy which is categorized as ' 0 ' for No and ' 1 ' for Yes. For example, in case of 'four and more ANC visits', for those women who had less than four ANC visits we assigned them as ' 0 ' whereas those women who had four \& more ANC visits we assigned them ' 1 '. The similar pattern is adopted for other outcomes variables in this study.

\subsection{Predictor variables}

The predictor variables are sex of the head of the household (male, female); mother's age group (15-24 years, 25-29 years, 30 years and above); mother's education (Incomplete primary, Primary and above); birth order (First order, Second order, Third order and above); social groups (SCs/STs, Non-SCs/STs); Religion (Hindu, Christian, Others); wealth quintile (poor, non-poor); place of residence (Urban, Rural); and Whether having exposure to mass media (No, Yes).

\subsection{Statistical analysis}

Descriptive statistics was used to show the distribution of the study population. Further, bivariate and multivariable logistic regression analysis was used to identify the factors associated with the outcome variable. A Chi-square test was performed to understand the association between outcome variables and predictors. And these variables were fitted in the multivariable logistic regression model to check its independent effect on each of the maternal health care use examined. The logistic regression model was defined as below: $\ln \left(\frac{p}{1-p}\right)=\alpha+\beta_{1} X_{1}+\beta_{2} X_{2}+\beta_{3} X_{3} \ldots \ldots \beta_{n} X_{n}+\varepsilon$

Where, $\mathrm{p}$ is the probability of utilization of health care and $\alpha$ is intercept, $\beta$ s are regression coefficients, $X$ is set of predictors and $\epsilon$ is an error term. STATA 13 was used to analyze data.

\subsection{Concentration index}

The study used wealth score for decomposition analysis and for the calculation of Concentration Index (CI). The wealth score was divided by ranking the score into five equal categories, each comprising $20 \%$ population. Concentration Index (CI) and Concentration curve (CC) was calculated to measure the socio-economic inequality in maternal health care use between hilly and valley region in the state of Manipur. Concentration index represents as twice the covariance of the health care outcome variable and an individual's relative ranking terms of economic status (wealth score in the present study), divided by the variable mean, as defined by the equation below. ${ }^{9}$

$C=\frac{2}{\mu} \operatorname{cov}\left(y_{i}, R_{i}\right)$

Where $\mathrm{C}$ is the concentration index; $y_{i}$ is the outcome variable index; $\boldsymbol{R}$ is the fractional rank of individual $i$ in the distribution of socio-economic position; $\boldsymbol{\mu}$ is the mean of the outcome variable of the sample, and $\boldsymbol{c o v}$ denotes the covariance. ${ }^{6}$ The index value lies between -1 and +1 .

\subsection{Decomposition of the concentration index}

The study used Wagstaff decomposition analysis to decomposing the concentration index. Wagstaff's decomposition demonstrated that the concentration index could be decomposed into the contributions of each factor to the income-related inequalities. ${ }^{10}$ Each contribution is the outcome of the sensitivity of health concerning that socio-economic factor and the extent of income-related inequality in that factor. Based on the linear regression relationship between the outcome variable $y_{i}$, the intercept $\alpha$, the relative contribution of $x_{k i}$ and the residual error $\varepsilon_{i}$

$y_{i}=\alpha+\sum \beta_{k} x_{k i}+\varepsilon_{i}$

Where $\varepsilon_{i}$ is an error term, given the relationship between $y_{i}$ and $x_{k i}$, the CI for y (C) can be rewritten as

$C=\sum\left(\frac{\beta_{k} \bar{x}_{k}}{\mu}\right) C_{k}+\frac{G C \varepsilon}{\mu} / \mu$

Where $\mu$ is the mean of $y_{i}, \bar{x}_{k}$, is the mean of $x_{k}, \beta_{k}$ is the coefficient from a linear regression of outcome variable, $C_{k}$ is the concentration index for $x_{k}$ (defined analogously to $\mathrm{C}$, and $\mathrm{GC}_{\epsilon}$ is the generalized concentration index for the error term $\left(\varepsilon_{i}\right)$.

Here $\mathrm{C}$ is the outcome of two components: First, the determinants or 'explained' factors, which are equivalent to the weighted accumulation of the concentration indices of the repressor, where one unit change in the outcome variable is to be associated with the one unit change in the explanatory variable. The explained factors indicate that the proportion of inequalities in the outcome variables ANC, institutional delivery and PNC is explained by the selected explanatory factors, i.e., $x_{k}$. Second, a residual or 'unexplained' factor $\left(\frac{G C E}{\mu} / \mu\right)$, indicating the inequality in health variable that cannot be explained by selected explanatory factors across various socioeconomic groups.

\section{Results}

The percentage distribution of the study population across both 
valley and hilly regions of the state by background characteristics. Overall, 33.4\% population resides in urban areas and even that highly varies between valley (47\%) and hills (9\%). In the wealth quintile, overall $42 \%$ of women belonged to the poor category. It varied between valley and hills regions as $32 \%$ to $61.4 \%$ respectively. In the distribution of social group, hill region are populated by SCs/STs with $96 \%$ as compared to only $13 \%$ in the valley region. The hills region is occupied by the Christian religion (94\%), however, the other religion category such as Muslims and other categories are mainly occupied in the valley region (Supplementary Table 1).

Table 1 depicts the level and pattern of maternal health care service utilization across hills and valley regions of the state with background characteristics. In the case of four and more ANC service, which is highly varied across hills and valley regions, further within the region it also found a huge difference in receiving maternal services with rural-urban areas. In the valley region with the urban resident, $84 \%$ of women have gone for four and more ANC visits as compared to $58 \%$ in the hills region. Regarding the mother's education category, women who have less than five years of schooling received $25.5 \%$ of ANC services in the hills region as compared to $60.5 \%$ in the valley region. While in the birth order of the child, receiving ANC services among women varied across regions. In the context of religion, the Hindu women belonged to the hills region are less affected by ANC services (received 61.4\%) compared to Christian women (received $41.7 \%$ ) in the same region, however, it varied from valley region as the Hindu women received $83 \%$ and Christian women $84.7 \%$ respectively.

In the case of institutional delivery among women between the regions of the state, it found that within the urban area, women belonged

Table 1

Percentage distribution of $\mathrm{MCH}$ services received by background characteristics across Valley and Hilly regions of Manipur state, India, 2015-16.

\begin{tabular}{|c|c|c|c|c|c|c|}
\hline \multirow[t]{2}{*}{$\begin{array}{l}\text { Background } \\
\text { Characteristics }\end{array}$} & \multicolumn{2}{|c|}{$4+$ ANC visit $^{\mathrm{a}}$} & \multicolumn{2}{|c|}{$\begin{array}{l}\text { Institutional } \\
\text { delivery }^{\mathrm{a}}\end{array}$} & \multicolumn{2}{|c|}{ PNC visit ${ }^{\mathrm{a}}$} \\
\hline & Valley & Hilly & Valley & Hilly & Valley & Hilly \\
\hline \multicolumn{7}{|l|}{ Mother age-group* } \\
\hline $15-24$ & 83.6 & 44.9 & 80.0 & 49.0 & 79.6 & 52.4 \\
\hline $25-29$ & 81.0 & 44.3 & 82.1 & 41.6 & 80.3 & 48.1 \\
\hline $30 \&$ above & 79.9 & 40.5 & 85.6 & 43.3 & 82.7 & 48.6 \\
\hline \multicolumn{7}{|l|}{$\begin{array}{l}\text { Sex of the Head of } \\
\text { Household* }\end{array}$} \\
\hline Male & 80.6 & 42.4 & 82.9 & 41.9 & 81.1 & 48.0 \\
\hline Female & 82.9 & 44.3 & 86.7 & 63.5 & 83.0 & 60.5 \\
\hline \multicolumn{7}{|l|}{ Child Birth Order* } \\
\hline First & 86.9 & 56.1 & 90.6 & 59.6 & 87.4 & 65.4 \\
\hline Second & 82.5 & 50.8 & 83.2 & 45.6 & 81.8 & 49.1 \\
\hline Three \& more & 68.3 & 31.5 & 69.9 & 32.7 & 70.3 & 41.3 \\
\hline \multicolumn{7}{|l|}{ Mother Education* } \\
\hline Incomplete primary & 60.5 & 25.5 & 60.4 & 24.7 & 58.4 & 33.5 \\
\hline Above Primary & 83.9 & 48.6 & 86.8 & 51.2 & 84.6 & 54.8 \\
\hline \multicolumn{7}{|l|}{ Wealth quintile* } \\
\hline poor & 67.1 & 26.6 & 66.0 & 27.5 & 66.2 & 35.4 \\
\hline non-poor & 87.0 & 65.9 & 91.6 & 70.1 & 88.0 & 69.6 \\
\hline \multicolumn{7}{|l|}{ Social group* } \\
\hline SCs/STs & 81.8 & 41.6 & 82.2 & 42.9 & 82.6 & 48.4 \\
\hline Non-SCs/STs & 82.5 & 58.5 & 83.6 & 60.0 & 81.9 & 63.4 \\
\hline \multicolumn{7}{|l|}{ Religion* } \\
\hline Hindu & 83.0 & 61.4 & 90.7 & 65.3 & 86.1 & 67.0 \\
\hline Christian & 84.7 & 41.7 & 82.5 & 43.0 & 82.4 & 48.5 \\
\hline Other & 76.7 & 43.8 & 71.5 & 45.8 & 72.6 & 48.7 \\
\hline \multicolumn{7}{|l|}{ Place of Residence* } \\
\hline Urban & 83.7 & 58.1 & 87.9 & 73.3 & 85.5 & 71.1 \\
\hline Rural & 78.4 & 41.1 & 79.5 & 41.2 & 77.6 & 47.2 \\
\hline \multicolumn{7}{|l|}{ Mass media* } \\
\hline No & 65.2 & 20.5 & 60.8 & 22.8 & 61.8 & 29.4 \\
\hline Yes & 82.3 & 49.9 & 85.6 & 51.9 & 83.1 & 55.9 \\
\hline $\mathbf{N}$ & 2737 & 1692 & 3214 & 2422 & 2737 & 1692 \\
\hline Total & 80.82 & 19.18 & 77.57 & 22.43 & 78.53 & 21.47 \\
\hline
\end{tabular}

Note: *Indicates significance at $5 \%$ level (i.e.: p-value $<0.05$ ); ${ }^{\text {a }}$ Chi-square test for categorical variables; SC/ST: Scheduled Caste \& Scheduled Tribe. to the hills region received $73 \%$ institutional delivery services as compared to $88 \%$, however, in the rural area; the differences were high between regions ( $41 \%$ in hills to $79 \%$ in a valley). Regarding the birth order of the child, the increased birth order of children among women has decreased in utilizing institutional delivery within and between regions of the state. Mother age has also affected the utilization of institutional delivery between regions. Exposures to mass-media among women have played a significant role in accessing and utilizing health services. Similarly, in receiving PNC among women between the regions, socio-economic and demographic factors always play a major role.

Table 2 shows the probability of different types of maternal healthcare services utilized by women with different predictor variables. As bivariate analysis clearly showed that there are huge variations in utilizing maternal healthcare services within and between groups across regions of the state. This multivariate analysis also showed that women who belonged to rural areas were less likely to be used of four and more

Table 2

Logistic regression model showed the association with predictor's variables in response to accessing $\mathrm{MCH}$ services in Manipur, India.

\begin{tabular}{|c|c|c|c|}
\hline $\begin{array}{l}\text { Predictor } \\
\text { variables }\end{array}$ & $\begin{array}{l}4+\text { ANC }(n=4214) \\
\text { OR }[95 \% \text { CI }]\end{array}$ & $\begin{array}{l}\text { Institutional } \\
\text { Delivery }(\mathrm{n}=5374) \\
\text { OR }[95 \% \mathrm{CI}]\end{array}$ & $\begin{array}{l}\text { PNC }(\mathrm{n}=4214) \\
\text { OR }[95 \% \mathrm{CI}]\end{array}$ \\
\hline \multicolumn{4}{|c|}{ Mother's age group } \\
\hline $15-24$ & Ref & Ref & Ref \\
\hline $25-29$ & $1.02(0.78-1.29)$ & $1.11(0.87-1.39)$ & $1.08(0.84-1.40)$ \\
\hline $\begin{array}{l}30 \text { and } \\
\text { Above }\end{array}$ & $1.10(0.85-1.41)$ & $1.83^{* * *(1.43-2.31)}$ & $\begin{array}{l}1.52^{* * *} \\
(1.16-1.96)\end{array}$ \\
\hline \multicolumn{4}{|c|}{ Sex of Head of the Household } \\
\hline Male & Ref & Ref & Ref \\
\hline Female & $1.02(0.78-1.32)$ & $1.58^{* * *(1.22-2.05)}$ & $1.23 *(0.93-1.62)$ \\
\hline \multicolumn{4}{|l|}{$\begin{array}{l}\text { Child birth } \\
\text { order }\end{array}$} \\
\hline First order & Ref & Ref & Ref \\
\hline Second order & $0.68^{* * *}(0.53-0.85)$ & $0.46^{* * *}(0.36-0.55)$ & $\begin{array}{l}0.51^{* * *} \\
(0.40-0.64)\end{array}$ \\
\hline $\begin{array}{c}\text { Three \& } \\
\text { more }\end{array}$ & $0.40 * * *(0.31-0.50)$ & $0.30^{* * *}(0.24-0.37)$ & $\begin{array}{l}0.39 * * * \\
(0.31-0.50)\end{array}$ \\
\hline \multicolumn{4}{|c|}{ Mother Education } \\
\hline $\begin{array}{l}\text { Less than } \\
\text { Primary }\end{array}$ & Ref & Ref & Ref \\
\hline $\begin{array}{l}\text { Primary and } \\
\text { Above }\end{array}$ & $1.65^{* * *}(1.32-2.05)$ & $1.66^{* * *}(1.36-2.01)$ & $\begin{array}{l}1.68 * * * \\
(1.35-2.07)\end{array}$ \\
\hline \multicolumn{4}{|c|}{ Wealth Quintile } \\
\hline Poor & Ref & Ref & Ref \\
\hline Non-poor & $3.03^{* * *}(2.52-3.64)$ & $3.55^{* * *}(2.97-4.23)$ & $\begin{array}{l}2.56 * * * \\
(2.11-3.08)\end{array}$ \\
\hline \multicolumn{4}{|l|}{$\begin{array}{l}\text { Social } \\
\text { groups }\end{array}$} \\
\hline $\mathrm{SC} / \mathrm{ST}$ & Ref & Ref & Ref \\
\hline Non-SC/ST & $1.60 * * *(1.14-2.23)$ & $1.82^{* * *}(1.31-2.51)$ & $\begin{array}{l}1.48^{* * *} \\
(1.07-2.04)\end{array}$ \\
\hline \multicolumn{4}{|l|}{ Religion } \\
\hline Hindu & Ref & Ref & Ref \\
\hline Christian & $0.44 * * *(0.31-0.61)$ & $0.34 * * *(0.24-0.47)$ & $\begin{array}{l}0.48^{* * *} \\
(0.34-0.67)\end{array}$ \\
\hline Others & $1.04(0.80-1.34)$ & $0.48^{* * *}(0.38-0.61)$ & $\begin{array}{l}0.66^{* * *} \\
(0.51-0.84)\end{array}$ \\
\hline \multicolumn{4}{|c|}{ Place of Residence } \\
\hline Rural & Ref & Ref & Ref \\
\hline Urban & $1.20^{* *}(0.96-1.48)$ & $1.65^{* * *(1.34-2.02)}$ & $\begin{array}{l}1.58^{* * *} \\
(1.28-1.96)\end{array}$ \\
\hline \multicolumn{4}{|l|}{ Region } \\
\hline Valley & Ref & Ref & Ref \\
\hline Hilly & $0.47^{* * *}(0.26-0.82)$ & $0.42^{* * *}(0.28-0.62)$ & $\begin{array}{l}0.42^{* * *} \\
(0.28-0.60)\end{array}$ \\
\hline \multicolumn{4}{|c|}{ Media Exposure } \\
\hline No & Ref & Ref & Ref \\
\hline Yes & $1.78^{* * *(1.42-2.22)}$ & $1.86^{* * *}(1.51-2.30)$ & $\begin{array}{l}1.75^{* * *} \\
(1.39-2.18)\end{array}$ \\
\hline
\end{tabular}

Note: Ref: refers to the base/reference group; SC/ST: Scheduled Caste \& Scheduled Tribe; *** p-value $<0.01$; ** p-value $<0.05$; * p-value $<0.1$. 
ANC services compared to urban women [OR; 1.20, CI; 0.96-1.48]. In reference to mother education, those women who had primary and above years of schooling were more likely to utilize ANC services compared to those who less than five years of schooling [OR; 1.65, CI; 1.32-2.05], similarly for religion, women belonged to Hindu community were more likely to utilize ANC services compared to Christian (OR; 0.40 , CI: $0.31-0.61$ ], in the wealth quintile, poor women were less likely to be utilized in the odds of non-poor women [OR; 3.03, CI; 2.52-3.64].

A similar pattern has also been seen in the institutional delivery. Among the social group, the odds of receiving institutional delivery among SC/ST women is lesser compared to non-SC/ST [OR; 1.82, CI; 1.31-2.51], further, women who had completed the primary and above schooling were more likely to go for institutional delivery [OR; 1.66, CI; 1.36-2.01] compared to those women who had less than five years. In reference to the wealth quintile non-poor women have more probability to utilize institutional delivery [OR; 3.55, CI; 2.97-4.23] compared to poor women. Head of the household was also found significantly with those who were female compared to male in the institutional delivery. Similar patterns were also seen in the PNC services. Socio-economic vulnerability appeared one of the important factors that influenced women in utilizing maternal and child health care services in the state.

\subsection{Concentration index and decomposition of concertation index}

Table 3 shows levels of inequality in ANC, institutional delivery, and PNC. At the state level, the inequality in ANC use is 0.161, inequality in institutional delivery is 0.184 and the inequality in PNC use is 0.147 . Inequality is significantly higher in hilly areas $\left(\mathrm{CI}_{\mathrm{ANC}}\right.$ :0.276; $\mathrm{CI}_{\text {inst.de- }}$ livery:0.277; $\mathrm{CI}_{\mathrm{PNC}}$ : 0.206$)$ than in valley regions $\left(\mathrm{CI}_{\mathrm{ANC}}: 0.070 ; \mathrm{CI}_{\text {inst.de- }}\right.$ livery 0.088 ; $\mathrm{CI}_{\mathrm{PNC}}: 0.081$ ). Both in hilly areas and the valley region the institutional delivery is more unequally distributed than ANC and PNC use.

Table 4 shows that both in the hilly region and valley region, the largest contributions to inequality in ANC use come from household wealth followed by access to television (12.8\%), and educational status (11\%). For example, inequality in household wealth contributed to $54 \%$ of the inequality in ANC use in a hilly region and household wealth contributed to $46 \%$ of the inequality in ANC use in valley areas, while access to television in the hilly region contributed to $12 \%$ of the inequality in ANC use and educational status of the women contributed to $3 \%$ of the inequality in ANC use in valley areas.

Similarly, in Table 5 it can be observed that household wealth contributes, even more, $56 \%$, of the inequality in institutional delivery in hilly regions while it contributed to around $33 \%$ of the inequality in institutional delivery in valley regions. Maternal education contributes $13 \%$ and $5 \%$ of the inequality in institutional delivery in hilly regions and valley areas respectively. Further, having access to television explained $12 \%$ of the inequality in institutional delivery in hilly regions.

Table 6 shows that actual contributions of household wealth are higher in hilly areas than valley areas for PNC. Similarly, observed determinants overall contributed to a greater percentage of inequality in PNC use in hilly areas than inequality PNC used in valley areas. Further Fig. 1 indicates high inequality in accessing institutional delivery and PNC visit in the hilly region, whereas low inequality in accessing all the three maternal healthcare services was observed in the valley region.

\section{Table 3}

Concentration Indices (CI) of outcomes variables across different hills and valley regions, Manipur state, India, 2015-16.

\begin{tabular}{|c|c|c|c|c|c|c|}
\hline \multirow[t]{2}{*}{ Regions } & \multicolumn{2}{|c|}{ Ante-natal Care } & \multicolumn{2}{|c|}{ Institutional Delivery } & \multicolumn{2}{|c|}{ Post-natal Care } \\
\hline & CI & S.E & CI & S.E & CI & S.E \\
\hline Hilly region & 0.276 & 0.014 & 0.277 & 0.011 & 0.206 & 0.013 \\
\hline Valley region & 0.070 & 0.006 & 0.088 & 0.004 & 0.081 & 0.005 \\
\hline Total & 0.161 & 0.006 & 0.184 & 0.005 & 0.147 & 0.005 \\
\hline
\end{tabular}

S.E: Standard Error.

\section{Discussion}

The present study investigates the different determinants of accessing ANC visits, institutional delivery, and PNC visits among 15-49 aged ever-married women in Manipur. We used the decomposition of concentration index method to further determine the inequality in accessing maternal healthcare services. In agreement with the previous study ${ }^{7,11}$ the result suggest that accessibility to ANC visit, institutional delivery, and PNC visit was significantly low among the ever-married women living in the hilly region of Manipur. Existing studies from Manipur and other parts of India acknowledge that the lack of health facilities and unavailability of proper transportation is the main deterrent factor for maternal health care use in the hilly areas. ${ }^{7,12}$ Further, the results reveal that factors such as social groups, maternal education, religion, childbirth order, exposure to media, and household economic status appear to have an effect on maternal health service use.

Caste was found to have an independent effect on the utilization of maternal health services. ${ }^{13}$ In agreement with the studies of Kumar and Singh, (2015) and Paul and Chouhan, (2020), ${ }^{14,15}$ our study show lower use of maternal healthcare services among the women belonging to the SC/ST communities. The possible explanation, for this reason, is mainly because these social groups are at a disadvantage across nearly all the determinants that affect maternal healthcare utilization. ${ }^{14}$ In addition, low economic status and education level was the result of low health status among the hilly tribal community in Manipur. ${ }^{11}$ Our finding regarding the positive association between women's education and utilization of maternal health services agrees with many previous studies in Nigeria, in Manipur, and in Africa and so on. ${ }^{7,16,17}$ Women who have acquired primary and above education were more likely to receive all maternal healthcare services with reference to the low educated women. ${ }^{18}$ The probable explanations for the low use of maternal healthcare services among the low educated women were due to the lack of knowledge about the availability, accessibility, and utilization and the other reason is that low educated women were not so open to discussing the different care at the time of pregnancy, delivery, and post-delivery. ${ }^{19}$ However, educated women may have a greater decision making power in and outside the household, have more confidence in communicating about their health problems, and have the ability and willingness to travel outside the home to seek care. ${ }^{20}$ Exposure to mass media increased the likelihood of women utilizing maternal healthcare services. ${ }^{21,22}$ The findings of this study also confirmed that exposure to mass media has a significant impact on maternal healthcare utilization. Evidence suggests that mass media such as reading newspaper, watching television, and listening to the radio is an effective information dissemination, which helps to access health care information and increases the awareness of people on healthcare facilities. $^{21,23}$

The effect of birth order which is consistent with the previous studies suggests that women are significantly more likely to use all maternal healthcare services for their first child. ${ }^{16,20}$ A study from India highlighted a sizeable proportion of young women reported having experienced at least one pregnancy-related complication during pregnancy, delivery, or postpartum period for the first pregnancy. ${ }^{24}$ Further, the study highlighted that care-seeking during the antenatal period and at delivery for the second and higher-order birth was limited as compared to the first birth. There are three possible explanations for this. First, women with a first child pregnancy pose a great health risk and probably more cautious about their pregnancy and hence more likely to seek maternal health care. ${ }^{25,26}$ Second, as the number of borne children increases, women may develop confidence and tend to believe that modern health care is not necessary and may rely on past experience and knowledge from previous pregnancies and birth. ${ }^{27}$ Third, a higher birth order indicates the greater family size and hence lack of time and money to seek formal health care. ${ }^{28}$ The problem due to cost, travel, and waiting time in accessing maternal health care services in the hilly district of Manipur is well documented in the previous studies. ${ }^{7,29}$ 
Table 4

Contributions of inequalities in determinants to inequalities in ANC use.

\begin{tabular}{|c|c|c|c|c|c|c|c|c|}
\hline \multirow[t]{2}{*}{ Background Characteristics } & \multicolumn{4}{|c|}{ ANC- Hilly } & \multicolumn{4}{|c|}{ ANC- Valley } \\
\hline & CI & Elasticity & Contribution & Contribution (\%) & $\mathrm{CI}$ & Elasticity & Contribution & Contribution (\%) \\
\hline Age $25-29$ years & -0.021 & 0.044 & -0.001 & -0.338 & -0.047 & -0.012 & -0.001 & -0.313 \\
\hline Age $30-49$ years & 0.034 & 0.082 & 0.003 & 1.017 & 0.095 & -0.026 & -0.002 & -0.906 \\
\hline SC/ST & 0 & 0.479 & 0 & -0.032 & -0.012 & 0.045 & -0.001 & -0.191 \\
\hline Below Primary & -0.33 & -0.093 & 0.031 & 11.156 & -0.482 & -0.022 & 0.011 & 3.913 \\
\hline Muslim & -0.204 & -0.002 & 0 & 0.151 & -0.369 & -0.011 & 0.004 & 1.493 \\
\hline Christians & -0.003 & 0.009 & 0 & -0.012 & 0.287 & 0.002 & 0.001 & 0.213 \\
\hline Second birth order & 0.058 & -0.055 & -0.003 & -1.164 & 0.048 & -0.01 & 0 & -0.177 \\
\hline Third birth order & -0.096 & -0.276 & 0.027 & 9.619 & -0.216 & -0.028 & 0.006 & 2.18 \\
\hline Rural & -0.036 & -0.121 & 0.004 & 1.575 & -0.143 & -0.007 & 0.001 & 0.346 \\
\hline Non-poor & 0.615 & 0.244 & 0.15 & 54.407 & 0.308 & 0.104 & 0.032 & 11.594 \\
\hline Reading news paper & 0.516 & 0.055 & 0.028 & 10.255 & 0.277 & 0.013 & 0.004 & 1.332 \\
\hline Listen to radio & 0.11 & 0.002 & 0 & 0.093 & 0.054 & 0.041 & 0.002 & 0.804 \\
\hline Watch television & 0.251 & 0.142 & 0.036 & 12.899 & 0.144 & 0.006 & 0.001 & 0.338 \\
\hline Female Head of the Household & 0.113 & -0.012 & -0.001 & -0.478 & 0.054 & 0.005 & 0 & 0.101 \\
\hline ANC & 0.276 & & 0.273 & 99.151 & 0.07 & & 0.057 & 20.728 \\
\hline Residual & & & 0.002 & 0.849 & & & 0.013 & 18.311 \\
\hline
\end{tabular}

Table 5

Contributions of inequalities in determinants to inequalities in institutional delivery.

\begin{tabular}{|c|c|c|c|c|c|c|c|c|}
\hline \multirow[t]{2}{*}{ Background Characteristics } & \multicolumn{4}{|c|}{ Institutional Delivery- Hilly } & \multicolumn{4}{|c|}{ Institutional Delivery- Valley } \\
\hline & $\mathrm{CI}$ & Elasticity & Contribution & Contribution (\%) & CI & Elasticity & Contribution & Contribution (\%) \\
\hline Age $25-29$ years & -0.021 & -0.027 & 0.001 & 0.204 & -0.047 & 0.006 & 0 & -0.341 \\
\hline Age $30-49$ years & 0.034 & 0.078 & 0.003 & 0.964 & 0.095 & 0.033 & 0.003 & 3.589 \\
\hline SC/ST & 0 & 0.331 & 0 & -0.022 & -0.012 & 0.019 & 0 & -0.261 \\
\hline Below Primary & -0.33 & -0.116 & 0.038 & 13.792 & -0.482 & -0.011 & 0.005 & 5.839 \\
\hline Muslim & -0.204 & -0.002 & 0 & 0.153 & -0.369 & -0.032 & 0.012 & 13.57 \\
\hline Christians & -0.003 & 0.005 & 0 & -0.006 & 0.287 & -0.009 & -0.003 & -2.95 \\
\hline Second birth order & 0.058 & -0.1 & -0.006 & -2.106 & 0.048 & -0.039 & -0.002 & -2.098 \\
\hline Third birth order & -0.096 & -0.298 & 0.029 & 10.338 & -0.216 & -0.037 & 0.008 & 9.056 \\
\hline Rural & -0.036 & -0.523 & 0.019 & 6.806 & -0.143 & -0.013 & 0.002 & 2.166 \\
\hline Non-poor & 0.615 & 0.255 & 0.157 & 56.622 & 0.308 & 0.097 & 0.03 & 33.798 \\
\hline Reading news paper & 0.516 & 0.032 & 0.017 & 5.962 & 0.277 & 0.026 & 0.007 & 8.129 \\
\hline Listen to radio & 0.11 & 0.015 & 0.002 & 0.575 & 0.054 & 0.001 & 0 & 0.068 \\
\hline Watch television & 0.251 & 0.138 & 0.035 & 12.483 & 0.144 & 0.031 & 0.005 & 5.107 \\
\hline Female Head of the Household & 0.113 & 0.036 & 0.004 & 1.477 & 0.054 & 0.005 & 0 & 0.328 \\
\hline Institutional Delivery & 0.277 & & 0.297 & 107.24 & 0.088 & & 0.067 & 76.002 \\
\hline Residual & & & -0.02 & -7.24 & & & 0.021 & 23.998 \\
\hline
\end{tabular}

Table 6

Contributions of inequalities in determinants to inequalities in PNC use.

\begin{tabular}{|c|c|c|c|c|c|c|c|c|}
\hline \multirow[t]{2}{*}{ Background Characteristics } & \multicolumn{4}{|c|}{ PNC- Hilly } & \multicolumn{4}{|c|}{ PNC- Valley } \\
\hline & $\mathrm{CI}$ & Elasticity & Contribution & Contribution (\%) & CI & Elasticity & Contribution & Contribution (\%) \\
\hline Age $25-29$ years & -0.021 & 0.013 & 0 & -0.137 & -0.047 & -0.003 & 0 & 0.181 \\
\hline Age $30-49$ years & 0.034 & 0.066 & 0.002 & 1.097 & 0.095 & 0.014 & 0.001 & 1.678 \\
\hline SC/ST & 0 & 0.359 & 0 & -0.032 & -0.012 & 0.023 & 0 & -0.34 \\
\hline Below Primary & -0.33 & -0.067 & 0.022 & 10.742 & -0.482 & -0.011 & 0.005 & 6.386 \\
\hline Muslim & -0.204 & -0.002 & 0 & 0.213 & -0.369 & -0.036 & 0.013 & 16.533 \\
\hline Christians & -0.003 & 0.083 & 0 & -0.139 & 0.287 & -0.001 & 0 & -0.391 \\
\hline Second birth order & 0.058 & -0.111 & -0.006 & -3.139 & 0.048 & -0.034 & -0.002 & -1.992 \\
\hline Third birth order & -0.096 & -0.235 & 0.023 & 10.916 & -0.216 & -0.026 & 0.006 & 6.946 \\
\hline Rural & -0.036 & -0.312 & 0.011 & 5.451 & -0.143 & -0.03 & 0.004 & 5.304 \\
\hline Non-poor & 0.615 & 0.169 & 0.104 & 50.393 & 0.308 & 0.095 & 0.029 & 35.775 \\
\hline Reading news paper & 0.516 & 0.011 & 0.006 & 2.847 & 0.277 & 0.041 & 0.011 & 14.073 \\
\hline Listen to radio & 0.11 & 0.048 & 0.005 & 2.569 & 0.054 & 0.012 & 0.001 & 0.782 \\
\hline Watch television & 0.251 & 0.139 & 0.035 & 16.932 & 0.144 & 0.02 & 0.003 & 3.539 \\
\hline Female Head of the Household & 0.113 & 0.015 & 0.002 & 0.843 & 0.054 & 0.005 & 0 & 0.345 \\
\hline PNC & 0.206 & & 0.203 & 98.556 & 0.081 & & 0.072 & 88.817 \\
\hline Residual & & & 0.003 & 1.444 & & & 0.009 & 11.183 \\
\hline
\end{tabular}

The study further provides important evidence to highlight the inequality in accessing maternal health use and identify the determinants. The result from the concentration indices suggests that the hilly region has high inequalities in maternal healthcare use as compared to the valley region. Further, after decomposition the inequality of maternal health services utilization, this study showed that women education, household wealth and watching television was the main contributor to inequality in maternal health services utilization in the hilly districts. This is because a substantial proportion of ST in the hills of Manipur is living below the poverty line due to low level of economic activity and high transportation cost further impact the utilization of maternal health services. ${ }^{8,11,30}$ The three concentration index 

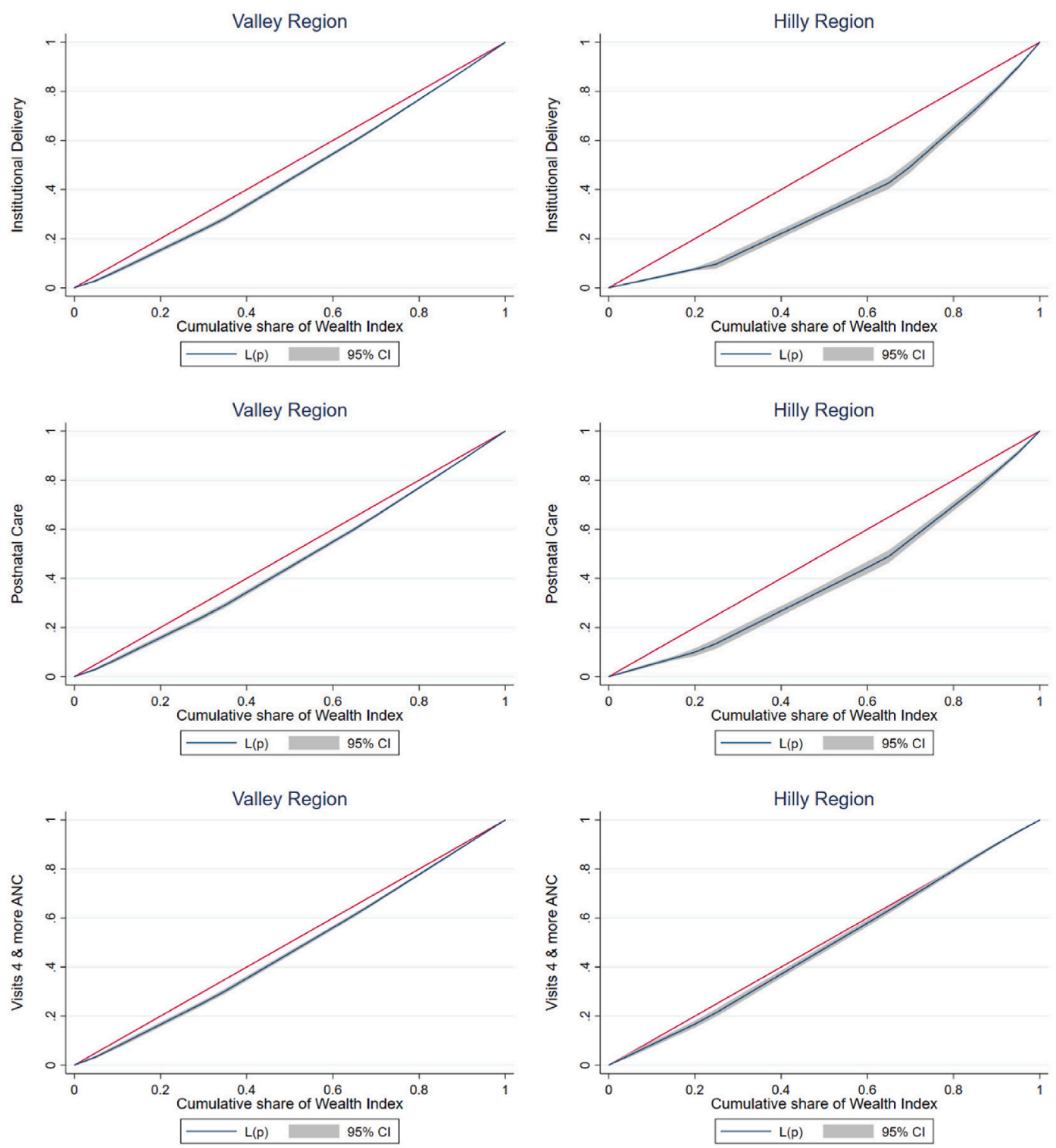

Fig. 1. Concentration curves showing inequality in maternal health care services between Valley and Hilly regions of State, $2015-16$.

of maternal healthcare services utilization (i.e. ANC visit, Institutional delivery, and PNC visit) were positive, suggest that a disproportionate share of maternal healthcare services resources is utilized by the richer people in spite of lower need. Compared to the valley, the inequality in institutional delivery and postnatal care was high in the hilly region of Manipur. The wide disparity between the valley and hill districts of Manipur in terms of health infrastructure, economic resources, job employment, level of economic activities and quality of education could be the reason for low health scores in the hilly region. ${ }^{11,31}$

The study has some limitations. First, the study relied on crosssectional data, the cause and effect cannot be investigated. Second, some known predictors of maternal health services use such as distance to health facilities are missing from our analyses. However, in spite of the above limitations, the study has some important findings which could be helpful for the policy implication.

\section{Conclusions}

In conclusion, this study demonstrates that there is a wide gap between the valley and hills in terms of utilizing maternal health services, as clearly depicted by the three major maternal health indicators. This suggests that strong effort must be made to address the issues of interstate variation of maternal health utilization in order to meet the sustainable development goal target in relation to infant and maternal mortality. The main reason for not utilizing maternal health services was the low level of education, poor household economic status, lack of women exposure to mass media, and women of higher parity, suggests that intervention programme and policymakers should focus on these vulnerable groups for improving the utilization of maternal health services. Improving the educational opportunity for women may have a big impact on the utilization of maternal health. However, this is a longterm investment. An alternative is a short term; health programme should target attracting women with little or no education. As women at higher parity levels were less likely to utilize maternal health, suggest that parity should be one of the conditions for targeting health education campaigns to increase the utilization of such programs. Lastly, improving the economic activities in the hilly region may indirectly increase the utilization of maternal health services.

\section{CRediT authorship contribution statement}

Prem Shankar Mishra: Conceptualization, Formal analysis, Writing 
- original draft. N. Pautunthang: Conceptualization, Writing - original draft. Strong P. Marbaniang: Writing - original draft, Writing - review \& editing. Anushree K. N: Formal analysis, Writing - review \& editing.

\section{Acknowledgement}

None.

\section{Appendix A. Supplementary data}

Supplementary data to this article can be found online at https://doi. org/10.1016/j.cegh.2021.100744.

\section{Funding}

This research did not receive any specific grant from funding agencies in the public, commercial, or not-for-profit sectors.

\section{Ethical statement}

NFHS data is publicly available, respondents de-identified and the institutional review board (IRB) of IIPS, Mumbai exempted from requiring IRB approval.

\section{Data source}

https://dhsprogram.com/data/dataset/India_Standard-DHS_2015. $\mathrm{cfm}$ ?lag $=1$.

\section{References}

1 Marchang R. Educational Development, and Household and Public Expenditures on Education in Manipur. Bangalore: ISEC Working paper; 2019. Report No.: 456.

2 Milan S. Widening Rift between the Valley and Hills of Manipur. The Economic Times; 2017. Available from https://economictimes.indiatimes.com/news/politics-and-nat ion/widening-rift-between-the-valley-and-hills-of-manipur/articleshow/57376876. $\mathrm{cms}$ ? from $=$ mdr.

3 Singh MD, Singh NS. Fertility indicators with hill-valley variations in Manipur. IOSR J Humanit Soc Sci. 2017 May;22(5):48-53. Available from http://www.iosrjournals. org/iosr-jhss/papers/Vol.22-Issue5/Version-7/I2205074853.pdf.

4 International Institute for Population Sciences (IIPS) and ICF. National Family Health Survey (NFHS-4), 2015-16:India. Mumbai: IIPS; 2017.

5 Phwam RL. Manipur Government Must Provide Equal Medical Facilities in Hills and Valley. IFP Bureau; 2020.

6 Singh MA. Conflicts in Manipur. National Institute of Advanced Studies. Indian Institute of Science Campus. Bangalore: NIAS Backgounder; 2010:1-52.

7 Thongkhanthang P. Access to maternal health services in rural Manipur. Int J Res Soc Sci. 2018;8(12):491-511. Available from https://www.ijmra.us/project.doc/2018/ IJRSS_DECEMBER2018/IJMRA-14865.pdf.

8 Singh TB. Poverty in Manipur. Econ Polit Wkly. 2007;42(3):251-254. Available from www.jstor.org/stable/4419165.

9 O'donnell O, Van Doorslaer E, Wagstaff A, Lindelow M. Analyzing Health Equity Using Household Survey Data: A Guide to Techniques and Their Implementation. The World Bank; 2007.

10 Wagstaff A, Paci P, van Doorslaer E. On the measurement of inequalities in health. Soc Sci Med. 1991;33(5):545-557.

11 Khan Y. Maternal health in Manipur. Journal of Development; 2012. Available from https://journalofdevelopment.wordpress.com/2012/10/05/maternal-health-in-man ipur/.

12 Joshi P, Mahalingam G, Sorte D. Factors influencing utilization of maternal and child health services among the postnatal mothers in hilly region. Int J Res Med Sci. 2016;4 (6):2170-2176. Available from http://www.msjonline.org/index.php/ijrms/article /view/882.
13 Hamal M, Dieleman M, De Brouwere V, de Cock Buning T. Social determinants of maternal health: a scoping review of factors influencing maternal mortality and maternal health service use in India. Publ Health Rev. 2020 Dec 2;41(1):13. Available from https://publichealthreviews.biomedcentral.com/articles/10.1186/s40985-02 0-00125-6.

14 Kumar A, Singh A. Explaining the gap in the use of maternal healthcare services between social groups in India. J Public Health. 2015 Dec 11;38(4):fdv142. Available from https://academic.oup.com/jpubhealth/article-lookup/doi/10.1093/pubmed/ fdv142.

15 Paul P, Chouhan P. Socio-demographic factors influencing utilization of maternal health care services in India. Clin Epidemiol Glob Heal. 2020 Sep;8(3):666-670. https://doi.org/10.1016/j.cegh.2019.12.023. Available from.

16 Babalola S, Fatusi A. Determinants of use of maternal health services in Nigeria looking beyond individual and household factors. BMC Pregnancy Childbirth. 2009 Dec 15;9(1):43. Available from http://bmcpregnancychildbirth.biomedcentral. com/articles/10.1186/1471-2393-9-43.

17 Tsala Dimbuene Z, Amo-Adjei J, Amugsi D, Mumah J, Izugbara CO, Beguy D. Women's education and utilization of maternal health services in Africa: a multicountry and socioeconomic status analysis. J Biosoc Sci. 2018 Nov 6;50(6):725-748. Available from https://www.cambridge.org/core/product/identifier/S00219320 17000505/type/journal_article.

18 Mishra PS, Syamala T. Multiple vulnerabilities in utilising maternal and child health services in Uttar Pradesh, India. Econ Polit Wkly. 2020;55(43):45-52.

19 Barman B, Saha J, Chouhan P. Impact of education on the utilization of maternal health care services: an investigation from National Family Health Survey (2015-16) in India. Child Youth Serv Rev. 2020 Jan;108:104642. https://doi.org/10.1016/j. childyouth.2019.104642. Available from.

20 Navaneetham K, Dharmalingam A. Utilization of maternal health care services in Southern India. Soc Sci Med. 2002 Nov;55(10), 1849-69. Available from https://linki nghub.elsevier.com/retrieve/pii/S0277953601003136.

21 Rai RK, Singh PK, Singh L. Utilization of maternal health care services among married adolescent women: insights from the Nigeria demographic and health survey. Wom Health Issues. 2008;22(4):e407-e414. https://doi.org/10.1016/j. whi.2012.05.001. Available from, 2012.

22 Singh L, Rai RK, Singh PK. Assessing the utilization of maternal and child health care among married adolescent women: evidence from India. J Biosoc Sci. 2012 Jan 21;44 (1):1-26. Available from https://www.cambridge.org/core/product/identifier/S00 21932011000472/type/journal_article.

23 Valente TW. Mass-media-generated interpersonal communication as sources of information about family planning. J Health Commun. 1996 Jul;1(3):247-266. Available from http://www.tandfonline.com/doi/abs/10.1080/108107396128040.

24 Santhya K, Jejeebhoy S, Ghosh S. Early Marriage and Sexual and Reproductive Health Risks: Experiences of Young Women and Men in Andhra Pradesh and Madhya Pradesh. India. New Delhi: New Delhi: Population Council; 2008. Available from htt ps://www.ohchr.org/Documents/Issues/Women/WRGS/ForcedMarriage/NGO/Po pulationCouncil22.pdf.

25 Jain S, Kurz K. New Insights on Preventing Child Marriage: A Global Analysis of Factors and Programs. International Center for Research on Women (ICRW); 2007. Available from http://www.icrw.org/docs/2007-new-insights-preventing-child-marriage.pdf.

26 Mirowsky J. Age at first birth, health, and mortality. J Health Soc Behav. 2005 Mar 23;46(1):32-50. Available from http://journals.sagepub.com/doi/10.1177/00 2214650504600104 .

27 Mekonnen Y, Mekonnen A. Utilization of Maternal Health Care Services in Ethiopia. Calverton, Maryland, USA: ORC Macro; 2002. Available from https://dhsprogram. com/pubs/pdf/fa38/01-mekonnen.pdf.

28 Wong EL, Popkin BM, Guilkey DK, Akin JS. Accessibility, quality of care and prenatal care use in the Philippines. Soc Sci Med. 1987 Jan;24(11):927-944. Available from https://linkinghub.elsevier.com/retrieve/pii/0277953687902863.

29 Mao LP. Factors Associated with Antenatal Care in Senapati District, Manipur, India. Sree Chitra Tirunal Institute for Medical Sciences and Technology; 2008:2009. Available from http://dspace.sctimst.ac.in/jspui/bitstream/123456789/1766/1/435.pdf.

30 De Onis M, Onyango AW, Borghi E, Siyam A, Nishida C, Siekmann J. Systematic review of inequalities in the use of maternal health care. Bull World Health Organ. 2007 Oct;85(10):812-819. Available from http://wwwwds.worldbank.org/extern al/default/WDSContentServer/WDSP/IB/2006/02/02/000160016_2006020216132 9/Rendered/PDF/351170Benefit0incidence0practitioner.pdf.

31 Zimik KT. Economic Backwardness of the Hills of Manipur: Revenue Sharing. The Sangai Express; 2020. Available from https://www.thesangaiexpress.com/Encyc/2020/ 10/29/Economic-backwardness-of-the-hills-of-Manipur-Revenue-sharing-.html.

32 Marbaniang Strong P. Women Care and Practices in the Management of Childhood Diarrhea in Northeast India. Child Care in Practice. 2020:1-13. https://doi.org/ 10.1080/13575279.2020.1812534. In press. 